\title{
TEKNIS-EKONOMIS PADI SAWAH IRIGASI UNTUK PENINGKATAN PENDAPATAN PETANI DI KABUPATEN NABIRE PAPUA
}

\author{
Afrizal Malik \\ Balai Pengkajian Teknologi Pertanian (BPTP) Jawa Tengah \\ Bukit Tegalepek Ungaran Semarang \\ Email: zea_rizal@yahoo.co.id
}

\begin{abstract}
Aim of this assessment is to study the behavior of farmers in the application of technology and to analyze irrigated rice paddy both input and output. Studies carried out in the center of irrigated lowland rice in Nabire, were doing the paddy rice farm implement at least two years. Primary data collection random proportionally in the form of a survey using questionnaires in April 2015 from the results of paddy rice cultivation MH (October/November 2014 and January/February 2015) as many as 43 farmers as respondents. Primary data includes cultivation technology, inputs and outputs. All data were tabulated and interprestation. Data were analyze in descriptive and quantitive way. The result showed that responses of farmers in this area depend on how the technology can improve paddy's productivity and the farmers income. The dynamics of the response of farmers to increase productivity technology is relatively stable, especially in components commonly applied to farmers in the cultivation of paddy (how is the tillage, weeding and fertilizer application). Technology components that are sensitive to productivity and affect the income of such varieties and fertilizers used almost similar to recommendation. Productivity produced 4.92 tonnes / ha dry milled grain with a profit rate of $R p$ 11,588,600 million (B/C 1.89). Furthermore, it is necessary to study about the use of fertilizer, because fertilizer recommendation just based on Phoska forecasts. Moreover, there must be effort to convince farmers to use Legowo technique to improve paddy's productivity. Scarcity of labor at planting and harvest need to be think in the future and also dissemination agricultural tools like (rice transplanter and a harvester/combine haevester) needs to be disseminated for farmers and stakeholders there.
\end{abstract}

Keywords: Technical, Economical, rice paddy.

Abstrak : Kajian ini bertujuan untuk mengetahui perilaku petani dalam penerapan
teknologi dan menganalisis input output usahatani padi sawah irigasi. Kajian
dilaksanakan di sentra padi sawah irigasi Kabupaten Nabire. yang melaksanakan
usahatani padi sawah minimal dua tahun terakhir. Pengumpulan data primer secara
acak sederhana secara proposional dalam bentuk survei menggunakan quisioner pada
bulan April 2015 dari hasil penanaman padi sawah MH (Oktober/November 2014-
Januari/Pebruari 2015) sebanyak 43 petani sebagai responden. Data primer meliputi
penerapan teknologi budidaya, input dan output. Semua data ditabulasi dan
diintreprestasikan. Analisis data secara deskripif dan analisis kuantitatif. Hasil kajian
menunjukan respon petani terhadap penerapan teknologi peningkatan produktivitas
padi sawah irigasi di Kabupaten Nabire saat ini sangat tergantung kepada seberapa
besar teknologi tersebut dapat meningkatkan produktivitas dan pendapatan petani.
Dinamika respon petani terhadap teknologi peningkatan produktivitas relatif stabil
terutama pada komponen yang lazim diterapkan petani dalam budidaya padi sawah
(cara olah tanah, penyiangan dan aplikasi pemupukan). Komponen teknologi yang
sensitif terhadap produktivitas dan berpengaruh kepada pendapatan seperti varietas 
dan dosis pupuk yang digunakan hampir mendekati anjuran. Produktivitas yang dihasilkan 4,92 ton/ha gkg dengan tingkat keuntungan Rp 11.588 .600 (B/C 1,89). Perlu dilakukan kajian penggunaan dosis pupuk, karena anjuran pupuk Phonska didasarkan prakiraan. Memberi keyakinan kepada petani jajar legowo meningkatkan produktivitas padi sawah. Kelangkaan tenaga kerja saat tanam dan panen, diseminasi alsintan seperti (transplanter dan rice harvester/combine haevester) perlu didiseminasikan ditingkat petani dan pemangku kebijakan di daerah.

Kata Kunci: Teknis, Ekonomis, Padi sawah.

\section{PENDAHULUAN}

Kebijakan Pemerintah Provinsi Papua dalam pembangunan sub sektor tanaman pangan, khususnya pengembangan padi selalu fokus, karena beras merupakan makanan pokok selain ubi jalar dan sagu serta banyak melibatkan tenaga kerja, serta mempengaruhi pertumbuhan ekonomi daerah. Berbagai program kebijakan pembangunan pada sub sektor ini telah dan sedang dilaksanakan diantaranya melalui program intensifikasi dan perluasan areal yang diusahakan secara simultan untuk mendukung peningkatan produktivitas padi (Malik dan Kadir, 2015).

Namun, usaha pengembangan padi tersebut belum banyak dan mampu mengangkat perekonomian yang lebih baik dalam meningkatkan kesejahteraan petani. Di kawasan sentra padi di Provinisi Papua masih jauh ketinggalan dalam perkembangannya. Hal ini disebabkan karena antara faktor bio fisik (sumberdaya lahan), sosial budaya (sumberdaya manusia dan kelembagaan), tekno-ekonomi dan politis (Malik dan Limbongan, 2008; lefaan, 2010). Rumitnya interaksi faktor-faktor tersebut menyebabkan adopsi inovasi sangat lambat yang bermuara pada tingginya tingkat kemiskinan dan kesejahteraan serta rendahnya ketahanan pangan (Sudaryanto dan Pranadji, 2006; lefaan, 2010).

Untuk itu perlu dilakukan terobosan teknologi spesifik lokasi agar pengguna mengadopsi teknologi sesuai kebutuhannya. Teknologi yang diciptakan harus efisien dalam arti biaya per unit produk yang dihasilkannya serendah mungkin sehingga mampu bersaing di pasaran, serta optimal yaitu mampu memanfaatkan sumberdaya lokal yang dimiliki petani secara seimbang dan maksimal (Sudana, 2005; Malik dan Limbongan, 2008).
Untuk mengurangi ketergantungan beras dari luar Papua, Pemerintah daerah melalui Dinas Tanaman Pangan dan Hortikultura (TPH) Provinsi Papua berupaya untuk mengenjot produktivitas melalui penerapan teknologi (intensifikasi) dan ektensifikasi padi sawah. Intensifikasi ini dalam rangka pemenuhan kebutuhan beras, diantaranya melalui penerapan PTT (Pengelolaan Tanaman Terpadu) di kawasan sentra yang potensial untuk dikembangkan sesuai dengan program pemerintah melalui Kementerian Pertanian. Bahkan sesuai SK kementan Nomor 1243/Kpts/OT.160/12/2014 tentang upaya khusus peningkatan produksi padi, kedelai dan jagung.

Menurut Dinas TPH Papua (2014) kebutuhan konsumsi beras di Papua 230.292 ton atau setara gabah 382.820 ton gkg dengan asumsi tingkat konsumsi beras 62,9 $\mathrm{kg} / \mathrm{tahun} / \mathrm{kapita}$, sedangkan kemampuan produksi 185.781 ton gabah gkg atau setara 111.468 ton beras. Jika disimak dari data diatas terjadi difisit (383.820 ton-185.781 ton) sebesar 198.039 ton, kemampuan produksi beras di Provinsi Papua hanya 52\%, difisit 42\%. Difisit ini didatangkan dari luar Papua (Sulawesi Selatan dan Jawa Timur).

Teknologi hasil penelitian/pengkajian pertanian merupakan bahan dasar untuk pengembangan inovasi teknologi terpadu yang dapat diterapkan dan sekaligus diadopsi oleh pengguna teknologi di lapang (Hendayana, 2010; Subagyono dan Kariyasa, 2012). Berbagai inovasi teknologi peningkatan produktivitas sudah banyak diterapkan di lapangan. Namun demikian, secara umum berdasarkan hasil evaluasi internal maupun eksternal, kecepatan dan tingkat pemanfaatan inovasi teknologi yang dihasilkan Balitbangtan cenderung melambat, dan bahkan menurun.

Penerapan inovasi teknologi pada komoditas-komoditas unggulan harus 
mempertimbangkan kondisi spesifik lokasi karena beragamnya faktor abiotik dan biotik, serta kondisi ekonomi, sosial dan budaya setempat. Oleh sebab itu, penerapan suatu inovasi teknologi pada berbagai kondisi spesifik lokasi, akan memerlukan upaya-upaya yang berbeda, khususnya dalam metode diseminasinya (Prijosusilo, 2011). Untuk itu perlu dilihat sejauhmana penerapan teknologi padi sawah tersebut diterapkan petani dan bagiamana tingkat keuntungan yang diperoleh.

Pengkajian bertujuan untuk mengetahui perilaku petani dalam penerapan teknologi peningkatan produktivitas padi sawah irigasi dan, (2) menganalisis input dan output usahatani padi sawah irigasi dan pendapatan di Kabupaten Nabire Papua.

\section{METODOLOGI}

Makalah ini merupakan bagian dari kegiatan PTT padi di Provinsi Papua. Kajian dilaksanakan di Kabupaten Nabire. Kabupaten Nabire adalah merupakan salah satu sentra padi sawah dan terluas kedua setelah Kabupaten Merauke di Provinsi Papua (Dinas TPH Papua, 2014; BPS Papua, 2015). Dari Kabupaten ini ditentukan Distrik Nabire Barat (Kampung Bumi Raya), Distrik Makimi (Kampung Biha) dan Distrik Wanggar (Kampung Bumi Mulia) sebagai sentra padi sawah irigasi terluas dan yang melaksanakan penanaman secara rutin minimal dua tahun terakhir.

Pengumpulan data primer menggunakan kuisioner terstruktur dan dikumpulkan proposional secara acak sederhana sebanyak 43 petani padi sawah sebagai responden berdasarkan luasan pengembangan padi sawah. Kajian dilaksanakan pada bulan April 2015 dari hasil penanaman padi sawah $\mathrm{MH}$ (Oktober/November 2014-Januari/Pebruari 2015).

Data primer yang dikumpulkan meliputi umur, pendidikan, penerapan teknologi budidaya padi sawah, input dan output dan dilengkapi dengan data sekunder yang terkait dengan kajian ini dari instansi yang relevan. Data yang sudah terkumpul ditabulasi dan dinterprestasikan. Analisis yang digunakan dalam pengkajian ini didasarkan pada dua pendekatan, yaitu analisis deskripsi dan analisis kuantitatif (Daniel, 2001).
Analisis deskriptif digunakan untuk mendeskripsikan keadaan umum usahatani padi sawah di daerah pengkajian. selain itu analisis deskriptif digunakan juga untuk mendeskripsikan gambaran atau penjelasan mengenai usahatani padi sawah irigasi. Dengan demikian metode analisis ini diharapkan mampu memberikan penjelasan tentang hal-hal yang berhubungan dengan usahatani padi sawah irigasi yang tidak dapat dijelaskan secara detail melalu analisis kuantitatif.

Analisis kuantitatif digunakan untuk menganalisis data yang berupa angka (Numerik) yang digunakan dalam menganalisis usahatani padi sawah. beberapa analisis kuantitatif yang dilakukan dalam pengkajian ini mengacu kepada formula yang lazim digunakan dalam analisis sederhana untuk penelitian/ pengkajian adalah FAO, (1993); Malian (2004); Manti dan Hendayana (2006); Malik dan Limbongan (2008):

Analisis biaya, produksi, penerimaan, pendapatan dan efisiensi usahatani padi sawah: (1) Total biaya produksi pada usahatani padi sawah: TC $=$ TFC + TVC. TC (Total cost), TFC (total fixed cost), TVC (variabel cost), (2) Penerimaan usahatani padi sawah: TR $=$ P.Q. TR (penerimaan usahatani padi sawah), $P$ (harga jual gabah) dan Q (hasil/gabah). (3). Efisiensi usahatani padi sawah. Untuk mengetahui apakah usahatani padi sawah telah efisien atau tidak, digunakan analisis B/C. B/C merupakan perbandingan antara hasil penjualan gabah dengan total cost dari seluruh biaya produksi yang telah dikeluarkan dalam usahatani padi sawah. Semua data dikonversi menjadi satuan hektar.

\section{HASIL DAN PEMBAHASAN}

\section{Keadaan umum daerah pengkajian}

Wilayah kajian didominasi daerah transmigran yang berasal dari pulau Jawa, NTT dan petani lokal (penduduk asli Papua). Kabupaten Nabire berbatasan langsung dengan Kabupaten Yapen Waropen di sebelah Utara, Kabupaten Dogiyai dan Kabupaten Kaimana di sebelah Selatan, Kabupaten Paniai dan Kabupaten Waropen disebelah Timur serta Kabupaten Teluk Wandama dan Kaimana di sebelah Barat. 
Afrizal Malik : Teknis-Ekonomis Padi Sawah Irigasi Untuk Peningkatan Pendapatan ...

Tabel 1. Luas daerah berdasarkan distrik dan jumlah kampung Kabupaten Nabire

\begin{tabular}{llccc}
\hline No & \multicolumn{1}{c}{ Distrik } & Luas $\left(\mathrm{Km}^{2}\right)$ & Rasio terhadap total $(\%)$ & Banyak Desa (satuan) \\
\hline 1 & Uwapa & $1.808,96$ & 15,06 & 6 \\
2 & Menou & $1.416,41$ & 11,79 & 4 \\
3 & Dipa & 838,63 & 6,98 & 5 \\
4 & Teluk Umar & 1.009 & 8,40 & 4 \\
5 & Wanggar & 611 & 5,09 & 4 \\
6 & Nabire Barat & 246 & 2,05 & 5 \\
7 & Nabire & 79 & 0,66 & 5 \\
8 & Teluk Kimi & 127 & 1,06 & 12 \\
9 & Napan & 178 & 1,48 & 5 \\
10 & Makimi & 1.006 & 8,38 & 8 \\
11 & Wapoga & 1.421 & 11,83 & 6 \\
12 & Siriwo & 1.040 & 8,66 & 5 \\
13 & Yaro & 830 & 6,91 & 6 \\
Jumlah & & 12.011 & 100,00 & 81 \\
\hline
\end{tabular}

Sumber: BPS Kabupaten Nabire (2014)

Dari luasan Kabupaten Nabire 12.011 $\mathrm{Km}^{2}(12.011 .000 \mathrm{Ha})$, yang terluas terdapat pada distrik Uwapa $\left(1.808,96 \mathrm{Km}^{2}\right)$ sedangkan yang tersempit terdapat pada Distrik Nabire Barat (79 $\mathrm{Km}^{2}$ ), yang menjadi lokasi kajian dan Distrik Makimi $\left(1.006 \mathrm{Km}^{2}\right)$ dan Distrik Wanggar 611 $\mathrm{Km}^{2}$ ). Rincian luas wilayah Kabupaten Nabire berdasarkan distrik dapat dilihat pada Tabel $1 \mathrm{di}$ bawah ini.

Kabupaten Nabire mempunyai rerata curah hujan $383,1 \mathrm{~mm} / \mathrm{bulan}$ dan curah hujan tertinggi terdapat pada bulan Nofember sampai Januari, dengan rata-rata hari hujan 18 hari/bulan. Sedangkan suhu rata terendah 23,8 $\mathrm{C}^{0}$ dan tertinggi $32,1 \mathrm{C}^{0}$ Jika disimak dari ratarata curah hujan dan hari hujan peluang pengembangan padi sawah sangat dimungkinkan (BPS Nabire, 2014).

Terdapat 192.666 hektar lahan basah yang sangat sesuai dan bisa dikembangkan untuk padi sawah dan 96.391 hektar lahan kering untuk pengembangan padi gogo (BPTP Papua, 2005). Disamping itu dukungan potensi irigasi yang mampu mengairi persawahan 8.000 an hektar dan sudah diusahakan untuk padi sawah sekitar 2.000 an hektar, yaitu bendungan irigasi Kali Bumi. Untuk mendukung pengembangan pertanian di Kawasan ini terdapat 7 buah BP3K (Balai Penyuluhan Pertanian, Perkebunan, Perikanan dan Kehutanan), PPL 101 orang dan terdapat luas pertanaman padi sawah 2.100 hektar (Distanbun Nabire, 2015).

Penduduk Kabupaten Nabire 132.348 jiwa (70.366 jiwa laki-laki dan 61.982 jiwa perempuan). Jumlah penduduk terbanyak terdapat pada distrik Nabire (35\%). Sedangkan penduduk yang menjadi lokasi pengkajian adalah distrik Wanggar 5,52\%, distrik Makimi 4,12\% dan penduduk Nabire Barat 8,23\% dari jumlah penduduk Kab. Nabire (BPS Nabire, 2014).

\section{Karakteristik responden}

Kemampuan petani dalam melaksanakan usahataninya sangat dipengaruhi oleh kemampuan fisik. Seseorang yang berada dalam usia produktif atau usia kerja akan bekerja lebih efisien dan kemampuan bekerja akan meningkat sampai mencapai umur tertentu kemudian akan menurun. Dari hasil kajian umur petani padi sawah didominasi pada usia produktif, 31-50 tahun (Tabel 2). Hal ini menunjukkan kemampuan kerja dalam usahatani padi sawah cukup tinggi. Menurut Amin (2014) umur kategori produktif berada 30-50 tahun.

Tingkat pendidikan formal petani tidak jauh berbeda dengan gambaran umum tingkat pendidikan petani pedesaan di Indonesia. Dari hasil kajian masih didapatkan petani yang setara dan tamat Sekolah Dasar $(9,26 \%)$ dan $62,79 \%$ tamat SLTP (Tabel 2). Disimpulkan tingkat pendidikan petani padi sawah di Kabupaten Nabire masih rendah. Rendahnya tingkat pendidikan ini akan menghambat proses diseminasi. Menurut Mulyandari (2011) petani dalam mengakses teknologi informasi cenderung memiliki pendidikan yang relatif tinggi, karena teknologi informasi merupakan media komunikasi baru yang membutuhkan pengetahuan yang reaktif tinggi dibanding dengan media komunikasi lainnya. 
Tabel 2. Karakteristik umur, pendidikan responden dan luas garapan padi sawah di Kabupaten Nabire, 2015.

\begin{tabular}{clcc}
\hline No & & Uraian & Persentase $(\%)$ \\
\hline 1 & Umur (Tahun) & 6,97 \\
& $\leq 30$ & 25,58 \\
& $31-40$ & 55,81 \\
& $41-50$ & 11,91 \\
& $\geq 51$ & \\
2 & Pendidikan & 9,30 \\
& SD & 62,79 \\
& SLTP & 23,25 \\
& SLTA & 4,66 \\
\hline
\end{tabular}

Sumber: data primer (2015)

Tabel 3. Penggunan benih dan statusnya dalam berusahatani padi sawah di Kabupaten Nabire, 2015.

\begin{tabular}{clc}
\hline No & \multicolumn{1}{c}{ Uraian } & Persentase (\%) \\
\hline 1 & Luas lahan garapan (ha) & \\
& $0,5-1$ & 58,14 \\
& $>1-1,5$ & 27,90 \\
& $>1,5-2$ & 9,30 \\
& $>2$ & 4,66 \\
2 & Varietas unggul baru (VUB) & \\
& a. Cigelius & 16,28 \\
& b. Ciherang & 39,53 \\
& c. Inpari 22 & 44,19 \\
3 & Sumber benih & \\
& a. Bantuan pemerintah & 30,23 \\
& b. Penangkar lokal & 39,53 \\
& c. Tukar tetangga & 20,93 \\
& d. Sendiri (hasil panen sebelumnya) & 9,31 \\
4 & Periode penggantian varietas & \\
& a. Tiap musim tanam & 4,63 \\
& b. Dua musim tanam & 16,28 \\
& c. Tiga musim tanam & 74,46 \\
d. Tidak menentu & 4,63 \\
Alasan pemilihan varietas & 27,90 \\
& a. Produktivitas tinggi & 30,23 \\
b. Harga jual beras tinggi & 37,27 \\
c. Ketahanan terhadap OPT & 4,63 \\
d. Umur panen pendek
\end{tabular}

Sumber: data primer (2015)

\section{Penampilan budidaya usahatani padi sawah}

Petani padi sawah yang ada di Kabupaten Nabire merupakan transmigran era tahun 1982an yang berasal dari Jawa Timur (Tulung Agung, Banyuwangi, Trengalek) dan Jawah Tengah (Boyolali, Purwodadi, Purworejo) dan NTT (Flores). Awal kedatangan para transmigran mendapat paket kepemilikan lahan masing-masing kepala keluarga 2 hektar dan sebagian petani membeli secara swadaya. Jika dilihat pada Tabel 3 terlihat kepemilikan lahan kepala keluarga relatif luas dan didominasi kisaran luas lahan sawah 0,5-1 hektar sebanyak $58,14 \%$.Dari kajian, petani yang mengusahakan usahatani sawah hampir rata-rata petani sehamparan mempunyai hand traktor untuk mengolah tanah. Hand traktor didapatkan dari bantuan pemerintah dan dibeli secara swadaya dan atau dengan cara kredit. Pola tanam yang adalah padi sawah-padi sawah-bera, padi sawah-padi sawah-kedelai/kacang tanah dan 
padi-sawah-padi sawah-sayuran (tomat, cabe, kubis).

Petani menggunakan varietas unggul diantaranya Inpari 22 lebih banyak disukai. Alasan yang dikemukakan petani karena produktivitas tertinggi dari hasil display varietas yang dilakukan BPTP Papua dan direkomendasikan Dinas Pertanian setempat. Petani masih menggunakan varietas Ciherang dan Cigelius dengan alasan rasanya nasi yang enak dan disenangi konsumen serta harga jual lebih tinggi. Hal senada juga dikatakan Sembiring (2008); Arsyad dan Jamal (2011); Taufik et al., (2011) bahwa varietas unggul merupakan inovasi teknologi berpeluang besar diadopsi petani, karena secara teknis mudah dilakukan, daya hasil tinggi dan tahan hama dan penyakit tertentu.

Petani dominan menggunakan benih berlabel, karena paket dari bantuan pemerintah melalui Dinas Pertanian, namun masih ditemukan petani menggunakan varietas tidak berlabel dengan alasan ketidakyakinan dari mutu benih yang diberikan, maka petani menggunakan dari benih sendiri dari hasil panen sebelumnya, bahkan tukar dengan petani tetangga yang mereka anggap cukup baik. Petani mengganti varietas setelah tiga kali tanam, alasan petani adalah produktivitas menurun dan tidak seragam penampilan di areal pertanaman. Alasan pemilihan varietas setiap petani cukup beragam namun didominasi pada ketahanan terhadap penyakit dan harga jual beras yang relatif tinggi dari varietas lain (Tabel 3).

Pengolahan tanah bertujuan untuk memperbaiki sirkulasi tanah agar didapatkan pelumpuran tanah yang baik dan sesuai untuk persyaratan pertanaman padi sawah. Dari hasil kajian, petani melakukan pengolahan tanah dengan traktor setelah itu dilakukan penyemprotan dengan herbisida, berselang $<10$ hari dilakukan penanaman. Petani melakukan penyiangan didominasi kombinasi herbisida dan manual yang didominasi dilakukan wanita. Petani melakukan penyemprotan herbisida pra tumbuh dengan jenis merek dagang DMA, Gramaxone dan Run Up. DMA digunakan untuk gulma yang berdaun lebar, sedangkan jenis Gramaxone dan Run Up digunakan pada tanaman pra tumbuh.
Petani mengusahakan padi sawah dengan sistem jajar legowo. Menurut Abdulrachman et al., (2013) sistem tanam jajar legowo adalah pola bertanam berselang seling antara dua atau lebih baris tanaman padi dan satu baris kosong. Baris tanaman (dua atau lebih) dan baris kosong (setengah lebar di kanan dan kirinya) disebut satu unit legowo. Bila terdapat dua baris tanam unit legowo disebut legowo 4:1. Petani mengetahui tentang legowo, terutama keunggulannya untuk meningkatkan populasi tanaman dan menggurangi serangan tikus, mudah penyiangan dan mudah dalam mengendalikan keong mas dan pertumbuhan tanaman lebih sehat dan seragam dan mudah dalam melakukan penyiangan.

Penerapan penanaman sistem jajar legowo oleh petani belum sesuai dengan kaidah sistem jajar legowo yang sebenarnya. Bagi petani yang penting lurus dan memudahkan dalam pemupukan dan penyiangan. Alasan yang dikemukakan petani adalah kelangkaan tenaga kerja saat tanam dan petani beranggapan terlalu rumit. Hal ini dapat dipahami, luasnya kepemilikan lahan setiap petani dan keterbatasan tenaga kerja saat dibutuhkan. Umur benih yang digunakan petani cukup beragam dengan kisaran 18-20 hss (hari setelah semai) dengan kisaran 2-4 batang perumpun tanaman.

Frekuensi pemupukan Urea didominasi petani dua kali, 2-7 hari hst (hari setelah tanam) dan menjelang masa primodia (60-65 hst). Sedangkan frekuensi pemberian SP-36 dan Phoska petani lebih banyak memberikan satu kali bersamaan dengan pemberian pupuk Urea dengan mencampur ketiga pupuk tersebut dan menghambur dalam barisan tanaman padi setelah penyiangan dilakukan. Tingginya serangan hama dan penyakit, petani melakukan lebih dari empat kali penyemprotan dengan menggunakan berbagai jenis pestisida berdasarkan tingkat serangan (Tabel 4).

\section{Keragaan teknologi padi sawah}

Peningkatan produktivitas padi sawah sangat dipengaruhi oleh pemberian input produksi diantaranya pupuk. Pemberian seharusunya tepat dosis dan aplikasi sehingga produktivitas optimal dapat dicapai. Petani menggunakan beberapa jenis pupuk diantaranya Urea, SP-36 dan Ponskha. Rendahnya penggunaan pupuk 
Tabel 4. Keragaan teknologi budidaya padi sawah di Kabupaten Nabire, 2015.

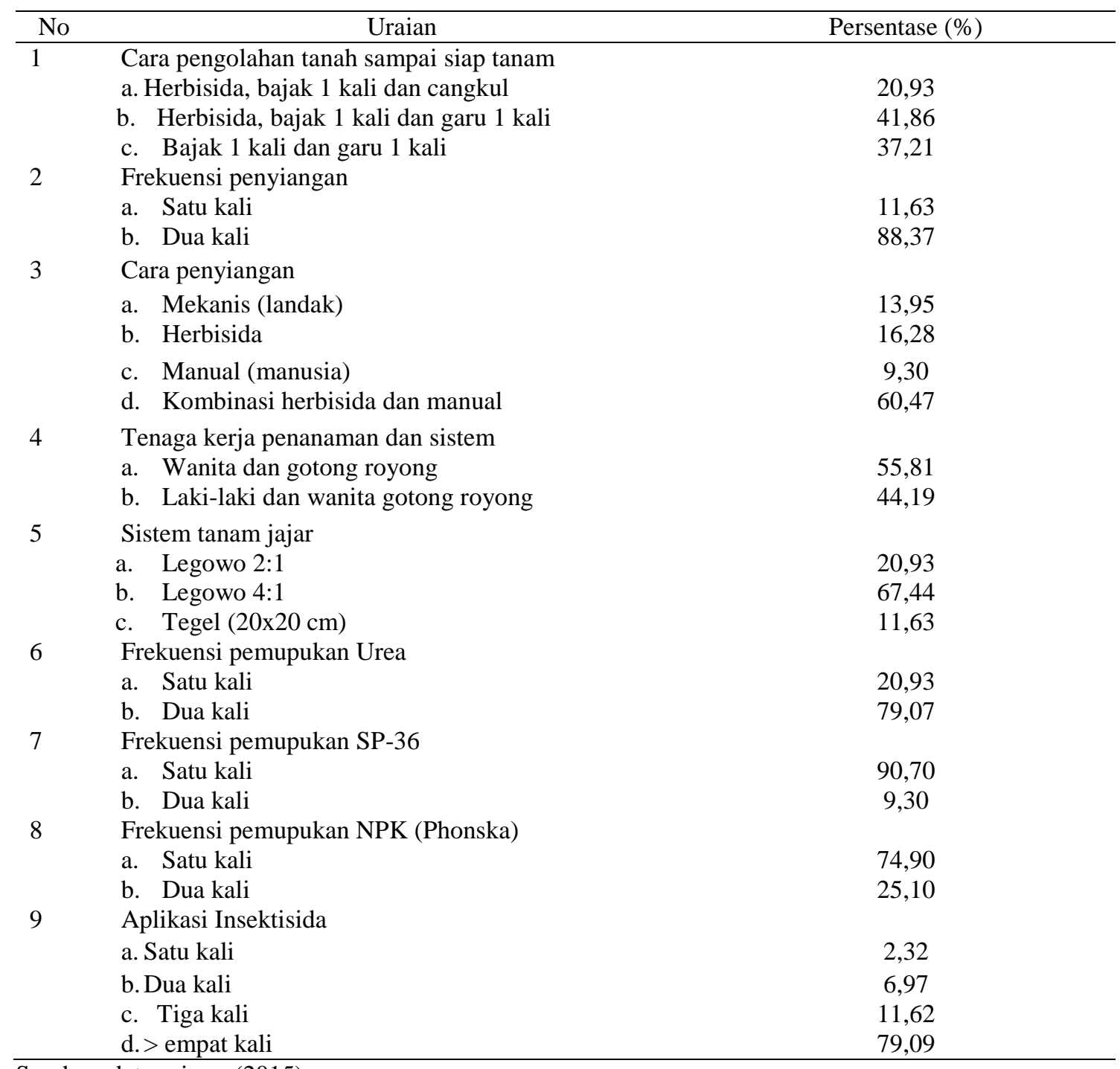

Sumber: data primer (2015)

oleh petani lebih banyak disebabkan ketersediaan pupuk belum tersedia tepat waktu dan aplikasi. Kalau itupun pupuk ada kelangkaan modal oleh petani sangat mempengaruhi dalam penggunaan pupuk yang diberikan kepada padi sawah. Hal senada dikatakan Malik dan Kadir (2015) penyebab lainnya rendahnya produktivitas padi sawah di sentra padi di Papua lebih banyak disebabkan penggunaan input yang rendah dan teknologi budidaya belum banyak dikuasai petani serta masalah sosial ekonomi seperti kelangkaan modal dan budaya. Disamping itu rendahnya produktivitas padi sawah yang dihasilkan di tingkat petani di sentra padi sawah di sentra produksi Papua menurut Djaenudin dan Hendrisman (2008) kurangnya hara untuk diperlukan penambahan pupuk organik, fosfat dan kalium sehingga hasil yang dicapai belum optimal.

Dari hasil kajian tingkat produktivitas padi sawah yang dicapai petani berkisar 4,805,4 ton//ha gkg dengan rata-rata 4,92 ton/ha gkg (Tabel 5). Hasil yang dicapai lebih rendah dari hasil pengkajian. Kasim et al., (2014) melaporkan produktivitas padi sawah varietas Inpari 22 mencapai 6,3 ton/ha gkg, sedangkan Rauf et al., (2009) dan Djufry et al., (2010) melaporkan produktivitas padi sawah di sentra produksi Papua dengan pemberian input sesuai dengan rekomendasi dan dikelola secara optimal produktivitas bisa dicapai 5,6-7,1 ton/ha gkg. Rendahnya produktivitas padi sawah yang dihasilkan petani tidak dipengaruhi 
Tabel 5. Kisaran dan rata-rata penggunaan pupuk dan produktivitas per hektar padi sawah irigasi di kabupaten Nabire, 2015

\begin{tabular}{llcr}
\hline No & Input & Kisaran & Rata-Rata \\
\hline 1 & Benih $(\mathrm{kg})$ & $26-33$ & 27,5 \\
2 & Pupuk (kg) & & \\
& - Urea & $100-125$ & 95,5 \\
& - SP-36 & $50-100$ & 83,50 \\
& - Phonska & $200-250$ & 256,5 \\
3 & Hasil (ton/ha) & $4,80-5,40$ & 4,92 \\
\hline
\end{tabular}

Sumber : Data Primer, 2015

Tabel 6. Analisis Input-Output usahatani padi sawah irigasi di Kabupaten Nabire Papua, 2015

\begin{tabular}{|c|c|c|c|}
\hline No & Uraian & Per hektar & $\%$ kontribusi \\
\hline 1 & Pengeluaran (Input) & 13.011 .400 & \\
\hline 2 & 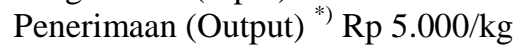 & 24.600 .000 & \\
\hline & a. Benih (Rp) & 275.000 & 2,11 \\
\hline & b. Pupuk (Rp) & 851.900 & 6,55 \\
\hline & c. Obat-obatan $(\mathrm{Rp})$ & 874.500 & 6,72 \\
\hline & d. Olah tanah (traktor) (Rp) & 1.000 .000 & 7,68 \\
\hline & d. Tenaga kerja (Rp 100.000/HOK) & 7.550 .000 & 58.04 \\
\hline & e. Upah treser $10 \%$ dari hasil & 2.460 .000 & 18,90 \\
\hline 3 & Total Keuntungan (2-1) (Rp) & 11.588 .600 & \\
\hline & $\mathrm{B} / \mathrm{C}$ & 1,89 & \\
\hline
\end{tabular}

Sumber: Tabel 5. ${ }^{*}$ harga gabah disesuaikan dengan harga yang berlaku di lokasi kajian

dosis pupuk yang diberikan, akan tetapi juga disebabkan faktor lingkungan dan musim tanam. Menurut Makarim dan Suhartatik (2009) produktivitas padi sawah merupakan hasil akhir dari pengaruh interaksi antara faktor genetik atas tanaman, lingkungan dan pengelolaan melalui suatu proses fisiologik dalam bentuk pertumbuhan tanaman.

Petani lebih banyak menggunakan benih, hal ini disebabkan ketidakyakinan petani terhadap mutu benih yang digunakan. Dosis pemupukan untuk padi sawah irigasi yang dianjurkan di sentra produksi Kabupaten Nabire adalah Urea 150 kg+100 kg SP-36+300 kg Phonska perhektar. Penggunaan dosis pupuk ini belum banyak dilakukan kajian, dosis pupuk yang ada didasarkan prakiraan dan mengacu kepada dosis pupuk secara umum. Kajian tentang dosis pupuk untuk peningkatan produktivitas padi sawah irigasi spesifik lokasi dikawasan ini sangat diharapkan.

Kontribusi terbesar dalam pembiayaan usahatani padi sawah irigasi adalah upah tenaga kerja (TK). Upah TK yang berlaku di lokasi kajian Rp 100.000/orang/ har. Upah TK penanaman, penyiangan dan panen memberikan kontribusi terbesar $(58,04 \%)$, disusul upah perontokan dengan tresher
$(18,90 \%)$. Pengeluaran terkecil berada pada pembelian benih. Jika semua biaya diperhitungkan kecuali nilai sewa lahan tidak dinilai maka keuntungan yang diterima petani sebesar Rp 11.588.600 perhektar.

Jika petani mengusahakan usahatani padi sawah selama 4 bulan, maka petani menerima keuntungan $\mathrm{Rp}$ 2.897.150/bulan. Keuntungan ini tidak jauh berbeda dengan upah minimum regional (UMR) Papua 2015 (Rp 2.853.000/bulan). Keuntungan ini dapat ditingkatkan, jika petani menerapkan teknologi peningkatan produktivitas padi sawah irigasi secara utuh.

\section{KESIMPULAN DAN IMPLIKASI KEBIJAKAN}

Respon petani terhadap penerapan teknologi peningkatan produktivitas padi sawah irigasi di kawasan sentra Kabupaten Nabire saat ini sangat tergantung kepada seberapa besar teknologi tersebut dapat meningkatkan produktivitas dan pendapatan petani. Dinamika respon petani terhadap teknologi peningkatan produktivitas relatif stabil pada komponen yang lazim dilakukan dalam budidaya padi sawah 
(cara olah tanah, penyiangan dan aplikasi pemupukan).

Komponen teknologi yang sensitif terhadap produktivitas dan berpengaruh kepada pendapatan seperti varietas dan dosis pupuk yang digunakan hampir mendekati anjuran. Kosekwensi dari pemberian input pada padi sawah, produktivitas yang dihasilkan 4,92 ton/ha gkg dengan tingkat keuntungan $\mathrm{Rp}$ 11.588.600 dengan nilai $\mathrm{B} / \mathrm{C} 1,89$. Usahatani padi sawah yang diupayakan petani di Kabupaten Nabire menguntungkan, karena B/C $>1$.

Perlu dilakukan kajian terhadap anjuran penggunaan pupuk, karena anjuran pupuk Phonska didasarkan prakiraan karena langkah dan mahalnya pupuk $\mathrm{KCl}$. Memberi keyakinan kepada petani jajar legowo meningkatkan produktivitas padi sawah. Kelangkaan tenaga kerja perlu penggunaan alat tanam (transplanter) serta alat panen perlu didiseminasikan ditingkat petani dan pemangku kebijakan di daerah.

\section{DAFTAR PUSTAKA}

Arsyad, D.M dan E. Jamal. 2011. Karakter Inovasi Teknologi Padi Sawah guna Percepatan Adopsinya. Prosiding Semnas dan Diseminasi Balai Besar Pengkajian dan Pengembangan Teknologi Pertanian Hal 1.473-1.481.

Abdulrachman, S., M.J. Mejana., N, Agustina., I, Gunawan., P, Sasmita dan A, Guswara. 2013. Sistem Legowo. Badan Litbang Pertanian.

Amin, M. 2014. Efektifitas dan Perilaku Petani dalam Memanfaatkan Teknologi Informasi Berbasis Cyber Extension dalam Elna et al., (eds). Inforomatika Pertanian. Vol. 23 (2) tahun 2014. Hal 211-219

BPTP Papua. 2005. Pewilayahaan Komoditas Pertanian Berdasarkan AEZ mendukung Agropolitan di Kabupaten Nabire. Laporan kegiatan TA 2005. Badan Litbang Pertanian.

BPS Nabire. 2014. Nabire Dalam Angka 2013. Badan Pusat Statistik. Nabire
Dinas TPH Papua. 2014. Kebijakan Pemantapan Ketahanan Pangan Provinsi Papua. Dinas Pertanian dan Hortikultura Provinsi Papua. Jayapura

Djufry, F., M.S. Lestari., Sudarsono., A. Kasim., A. Malik., D. Wamaer., A. Soplanit dan S.R. D. Sihombing. 2010. Pendampingan Program Sekolah Lapang Pengelolaan Tanaman Terpadu. Laporan kegiatan TA 2010. BPTP Papua. Balai Besar P2TP. Badan Litbang Pertanian

Daniel, M. 2001. Metode Penelitian Sosial Ekonomi. Penerbit Bumi Aksara. Jakarta.

Distanbun Nabire. 2015. Program Kebijakan Pengembangan Padi sawah di Kabupaten Nabire. Dinas Pertanian dan Perkebunan Kabupaten Nabire.

FAO. 1993. Farming System Development: A. General Guideline. FAO. Roma

Hendayana, R. 2010. Disain Model Percepatan Adopsi Inovasi Teknologi Unggulan Badan Litbang Pertanian. Prosiding Seminar Nasional di Cisarua, 9-10 Desember 2010. Balai Besar P2TP. Badan Litbang Pertanian. Buku 2 hal. 1.055-1.062.

Kasim, A dan S. Kadir. 2014. Display Beberapa VUB pada Padi Sawah Irigasi di Kabupaten Nabire, Papua. laporan Kegiatan TA 2014. BPTP Papua. Balai Besar P2TP. Badan Litbang Pertanian

Lefaan, A. 2010. Adaptasi Teknologi Pertanian Spesifik Lokasi Mendukung Ketahanan pangan Agrobisinis Perdesaan Pendekatan Sosiologi Pembangunan Pertanian. Prosiding Seminar Nasional BPTP Papua. Kerjasama Balai Besar P2TP dengan Pemerintah Daerah Provinsi Papua. Jayapura, 7-8 Oktober 2010. Hal 12-19.

Malian, A.H. 2004. Analisis Ekonomi Usahatani dan Kelayakan Finansial Teknologi pada Skala Pengkajian. Materi Disampaikan dalam Pelatihan 
Analisis Finansial dan Ekonomi Bagi Pengembangan Sistem Usahatani Agribisnis Wilayah. Puslit Sosial Ekonomi Pertanian. Bogor, 29 November-9 Desember 2004.

Mulyandari, R.S.H. 2011. Perilaku Petani Sayuran dalam Pemanfaatan Teknologi Informasi. Jurnal Perpustakaan Pertanian 20 (1) 22-24. Badan Litbang Pertanian.

Makarim, K dan Suhartatik. 2009. Morfologi dan Fisiologi Tanaman Padi. Padi Inovasi Teknologi dan Ketahanan Pangan. Balai Besar Penelitian Padi. Buku I. Hal. 295-330.

Malik, A dan Syafruddin Kadir. 2015. Mengenjot Produksi Padi Sawah Kabupaten Merauke, Papua. Bunga Rampai "Menguak Potensi Teknologi Spesifik Lokasi Guna Mancapai Kesejahteraan Petani. ISBN: 978-60271644-3-7. Penerbit: Kristal Multimedia, Bukittinggi April 2015.

Prijososulo, B. 2011. Brain-Brain dan Fragmentasi Sosial yang Menyengsarakan Masyarakat Petani dalam Subejo., et al (eds) Prosiding Semnas Hasil Penelitian Sosial Ekonomi Pertanian. Universitas Gajah Mada. Hal 456-467.

Sudana, W. 2005. Evaluasi Kinerja Diseminasi Teknologi Integrasi Ternak Kambing dan Kopi di Bongancina, Bali. Jurnal Sosial Ekonomi Pertanian dan Agribisnis SOCA. Vol 5 No.3. Fakultas Pertanian Universitas Udayana. Denpasar. hal 326333.
Sudaryanto, T dan T. Pranadji. 2006. Transformasi Kelembagaan untuk Percepatan Adopsi Teknologi Pertanian pada Masyarakat Papua. dalam Limbongan et al., (eds). Prosiding seminar Nasional BPTP Papua. kerjasama BBP2TP dengan Pemerintah Provinsi Papua. Jayapura, 24-25 Juli 2006.

Sembiring, H. 2008. Kebijakan Penelitian dan Rangkuman Hasil Penelitian Balai Besar Padi dalam Mendukung Peningkatan Produksi Besar Nasional. Prosiding Seminar Apresiasi Balai Besar Tanaman Padi Sukamandi. Subang

Taufik, M., Raliman dan R. Hermawan. 2011. Analisis Produktivitas Padi Sawah di Kupang Timur Nusa Tenggara Timur. Jurnal Ilmu Ilmu Pertanian, 8 (2):105114.

Rauf, A.W., Musrifah., Syamsudin dan M. Maulud. 2004. Teknologi Budidaya Padi dengan Sistem Tabela pada Lahan Sawah Irigasi dan Tadah Hujan di Kabupaten Merauke. Prosiding Seminar Nasional BPTP Papua, Jayapura 5-6 Oktober 2004. Puslitbang Sosial Ekonomi Pertanian. Badan Litbang Pertanian Hal 105-112.

Subagyono, K dan K. Kaiyasa. 2012. Dampak Prima Tani Terhadap Pemanfaatan dan Produktivitas Sumberdaya Lahan dan Pendapatan Rumah Tangga Petani. Jurnal Pengkajian dan Pengembangan Teknologi Pertanian. Vol 15 (1) Maret 2012. Hal.69-81. 